\title{
Study on College Students' Spare Time Management
}

\section{Chunming $\mathrm{Xu}^{1, \mathrm{a}}$, Can Wang ${ }^{1, \mathrm{~b},{ }^{*}}$ and Nan Yang ${ }^{1, \mathrm{c}}$}

\author{
${ }^{1}$ No.999-26, Bingang Road, Lvshunkou Economic Development Zone, Dalian City, Liaoning \\ Province, China \\ a652196979@qq.com, b297413904@qq.com, c872949965@qq.com \\ ${ }^{*}$ Corresponding author
}

Keywords: college students, spare time, management, higher education

\begin{abstract}
Since human beings entered the post-industrial society, leisure life has occupied an increasing proportion in people's life. China began to implement the two-day system from May 1, 1995. With the continuous introduction of a series of policies and systems, the time of studying in school has been reduced to 190 days per year, but increased to more than 170 days after school. The spare time of college life is very sufficient, which is an important part of college students' continuing socialization, and plays an important role in the cultivation of college students' personality and the formation of the three concepts. This paper expounds the necessity of cultivating the ability of managing spare time, analyzes the problems in managing spare time and puts forward some corresponding suggestions.
\end{abstract}

\section{Introduction}

The rapid development of science and technology, the rapid progress of the Internet and the wide application of high-tech products have brought about many changes in people's lives. They make people's life more and more diversified and colorful. They constantly enrich people's lives. Of course, people also have more spare time. Although people's leisure activities are various, how to effectively use and manage spare time is becoming more and more important. For college students, college is an important period for personal growth and self-improvement, as well as a preparatory period for entering the workplace. It is also a crucial period for the formation of their world outlook, outlook on life, values and comprehensive abilities. Einstein once said, "The difference between people lies in their spare time." Lu Xun also once said: "Where there is a genius, I am the other people's coffee time spent on writing." ${ }^{[1]}$ It can be seen that if we can make good use of our spare time in college, it will have more positive effects on one's growth.

\section{The necessity of cultivating the ability of managing college students' spare time}

\subsection{The importance of training talents}

Bornov, the famous German educator, he once said: "The first task of education is that educators should leave time for themselves, to leave time for education. The second task of education is to make people fully aware of the importance of after-school time management so that they can make positive use of it. ${ }^{[2]}$ For college students, since there is no specific requirement to do in their spare time, they can freely allocate their spare time. Secondly, I have enough spare time, even more than the class time. The above two points determine that college students' ability to manage time is mainly reflected in the management of spare time. In extracurricular activities, on the one hand, students can apply the knowledge and skills acquired in class to practice, so as to test whether they have really mastered what they have learned. On the other hand, through various activities in spare time, we can learn things that cannot be learned in class. Activities in spare time play an important role in broadening our knowledge structure and cultivating our innovation ability. 


\subsection{Help to Alleviate the Psychological Problems of College Students}

The research of zhang zhijie and huang xiting shows that time management is a good predictor of academic performance. That is to say, the better students' time management ability is, the more conducive to the generation of positive emotions, while the worse their time management ability is, the less conducive to the generation of positive emotions. ${ }^{[3]}$ Therefore, students' time management level is one of the important factors affecting students' subjective well-being. Therefore, the school should attach importance to the cultivation of college students' time management ability, especially their spare time. There are ten subscales under this scale, and the time management subscale is one of them. In addition, Weinstein et al. also found that the higher the score on other subscales, the higher the score on the time management subscale, with a correlation of 0.74 to the motivation subscale, 0.59 to the attitude subscale, and 0.68 to the attention focus subscale. Therefore, we come to the conclusion that improving the time management ability of college students is equal to improving their independent learning ability, which is of great significance for college students to enter the society and enter the workplace in the future.

\section{Management Status Quo and Problems in College Students' Spare Time}

\subsection{There are various forms of extracurricular activities, but students' choices are too simple}

With the increase of college students' spare time, their spare life is also diversified, rich in content and various in style. The contents involved include: expanding learning of classroom knowledge, various club activities, associations organized by students with various specialties and hobbies, extracurricular fitness, volunteer activities, etc. ${ }^{[4]}$ In a word, today's college life has completely changed the previous monotonous model, become more and more diversified, conform to the requirements of The Times, comprehensive development in many aspects, including some universities now carry out some extracurricular optional courses for students to choose interest, continue to enrich college students' extracurricular life. However, students' choice is too single, only choose one or several to experience, think it is not fresh or fun will not touch again, some even stay in the dormitory, watching TV, surfing the Internet, eating are just takeout. Are these problems caused by students' lack of self-management ability? Whether schools and society should pay enough attention to such problems and adopt some relevant policies.

\subsection{Most of the spare time is used for entertainment, with less time for study}

According to the statistics of relevant departments: our average sleep time every day is 8 hours, excluding this 8 hours of sleep time, according to the calculation of each class 45 minutes, 40 classes a week, so the class time is 1800 minutes, and after school time is 4920 minutes, about three times more than the class time. So how do college students allocate and use their time? According to the survey shows that most of the students are used to entertainment, such as Internet, chase play, shopping, songs, movies, etc., there are some people used to do part-time jobs or volunteer activities to enrich their experience, very few people involved for learning class or no digestion of knowledge, and most of the students will choose to studying right near a week before the exam, though it has become a popular a kind of practice in the university. When analysis the causes of this student is not reasonable use after school time, experts draws the conclusion that the students have just finished high school of that kind of pressure management mode, to enter university, in a totally different from before the management pattern, the students on the one hand, to be curious about the new management mode on the one hand, due to the effect of the spread of some senior students thoughts, think that university is easier than high school, more use of university time to relax. However, the university depends on students' self-control ability, can not overindulge themselves, otherwise it is a waste of a good study time. In short, the utilization rate of college students' spare time is generally not high. ${ }^{[5]}$ If relevant measures and policies are not taken to change this situation, will the quality of higher education predicted by experts be lower than that of secondary education in the long run? 


\subsection{Less time for physical exercise in spare time leads to low psychological quality}

Today's college students is generally not strengthen the consciousness of physical exercise, causes our country college students' physical quality is bad, in order to improve the situation on many colleges and universities to implement the measures of morning exercises, the students are not in favor of this practice, however, use a variety of excuses and reasons to escape morning exercises, some even protest school policy, reason is surprising, they think all college students also do primary school students. Whether the emergence of this problem reflects such a problem: that contemporary college students not only because of lack of physical exercise and physical decline, and psychological mechanism is not mature. If do not strengthen physical exercise, not only the physical quality of students can not go up, psychological quality is getting worse. Nowadays, college students commit suicide frequently because of psychological problems, which is a matter that the whole society should pay attention to. College students shoulder the mission of serving the country, why such heartache and regret frequently occur, which is very thought-provoking.

\section{Suggestions for College Students to Manage Their Spare Time Reasonably}

\subsection{Pay attention to the cultivation of college students' values in their spare time}

Lu Xun once said, "Wasting one's own time equals to chronic suicide, while wasting others' time equals to murder". ${ }^{6]}$ As a college student should have a correct concept of time, for their own spare time learn to reasonable use of the precious resources, both neither can day and night for various examination certificate of immersed in the book knowledge, also can not to overindulge, waste valuable time on entertainment activities such as singing, shopping, shopping. It is very important to cultivate the correct concept of time for college students, because a life in perfect order must be a person who knows how to manage their time, so that they learn to their spare time for a reasonable allocation, use, evaluation, the maximum use of these time due to value.

\subsection{Introduce the cultivation of spare time management skills into the classroom}

It is imperative to include the cultivation of college students' extracurricular time management skills into the classroom. According to the feedback from the interview, colleges and universities have not explicitly included the cultivation of college students' extracurricular time management skills into the curriculum, which indicates that the cultivation of college students' extracurricular time management ability has not yet entered the classroom. Why do you want to introduce the college students in their spare time management skill training class, first of all, the classroom is a organized and discipline and a unified centralized management system and the size of the organization, their spare time management skills in classroom, can undertake to the student concentrated and efficient training, have twice the result with half the effort. Secondly, teachers play a leading role in the classroom, can guide students accordingly, so that students less detour, can quickly achieve the corresponding training objectives. Finally, because of the class teaching mode in the classroom, students can communicate with each other about the skills they have learned, which helps students to develop their strengths and avoid their weaknesses, and improve their management skills in spare time.

\subsection{Attach importance to the theoretical research on the cultivation of college students' extracurricular time management ability}

Colleges and universities should set up theoretical research institutions on college students' ability to manage their spare time, because theory is the basis of practice, which cannot be successfully realized without the guidance of theory. The purpose of this institution is to conduct a systematic study on the curriculum, training, evaluation and other aspects of college students' ability to manage their spare time, so as to further improve the current situation in which college students cannot make rational use of their spare time. For the development and compilation of curriculum, the expert group, as a research institution, needs to give a clear guide to teachers, and present the training objectives in the course compilation in a specific and clear way, so that teachers can teach in accordance with their aptitude in the course implementation process and take appropriate measures. ${ }^{[7]}$ In the actual training 
of students, pay attention to the combination of relevant theories, give students correct guidance, at the same time can not be mechanically training, pay attention to the creation and construction of the situation, so that students as far as possible to devote themselves. For this aspect of evaluation, we should try to combine the performance of students in practical training to evaluate, but also pay attention to the study of students' extracurricular time management ability theory, to achieve the combination of theory and practice, make a positive judgment and evaluation of students' performance.

\section{Conclusion}

College students' spare time is an important part of college life, so we must pay attention to the cultivation of their time management ability. Efficient and active use of spare time for the healthy growth of college students is extremely beneficial. College students shoulder the mission and heavy responsibility of constructing the motherland, only by training them in quality and quantity can our country realize the transformation from a big country in higher education to a powerful country in higher education. However, this is a long and arduous project, which needs the help and support from all walks of life. It is difficult to complete it successfully only by teachers and students. College students' ability to manage their spare time is enhanced, which is not only beneficial to their future career, but also beneficial to their physical and mental health, and more able to train a large number of qualified successors for the motherland. Therefore, the cultivation of college students' ability to manage their spare time deserves the attention and attention of the whole society and even the country.

\section{References}

[1] Pang Guimei, Leisure education, Nanjing: jiangsu education press, pp.12-14, 2004.

[2] Jia Dongrong, Zhou Ergan, Song Xiaodeng et al, Research and development trend of time management for college students, Journal of youth, vol.3, pp.48-49, 2017.

[3] Xia Lili, Investigation and research on the allocation of college students' spare time, Knowledge economy, vol.4, pp.24-30, 2011.

[4] Yu peng, Li Jianwei, Research on the structure and characteristics of college students' spare time management, psychological science, vol.2, pp.13-27,2010.

[5] Zhang Xiuling, A preliminary study on college students' behavior in leisure time travel activities, Journal of shanxi normal university (social science edition), vol.4, pp. 182-184,2014.

[6] Chen Dekui, On leisure education for college students, Jiangsu higher education, vol.5, 2007.

[7] Hu Xiaoyan, Liu Zhanhui, On college students' leisure life and leisure education, Journal of Jilin university of architecture and engineering, vol.6, 2014. 